\title{
Real power loss reduction by tundra wolf algorithm
}

\author{
Kanagasabai Lenin \\ Department of EEE, Prasad V. Potluri Siddhartha Institute of Technology, India
}

\begin{tabular}{l} 
Article Info \\
\hline Article history: \\
Received Nov 16, 2019 \\
Revised Jan 17, 2020 \\
Accepted Feb 11, 2020 \\
\hline
\end{tabular}

\section{Keywords:}

Optimal reactive power

Transmission loss

Tundra wolf algorithm

\begin{abstract}
In this work Tundra wolf algorithm (TWA) is proposed to solve the optimal reactive power problem. In the projected Tundra wolf algorithm (TWA) in order to avoid the searching agents from trapping into the local optimal the converging towards global optimal is divided based on two different conditions. In the proposed Tundra wolf algorithm (TWA) omega tundra wolf has been taken as searching agent as an alternative of indebted to pursue the first three most excellent candidates. Escalating the searching agents' numbers will perk up the exploration capability of the Tundra wolf wolves in an extensive range. Proposed Tundra wolf algorithm (TWA) has been tested in standard IEEE 14, 30 bus test systems and simulation results show the proposed algorithm reduced the real power loss effectively.
\end{abstract}

This is an open access article under the CC BY-SA license.

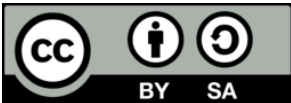

\section{Corresponding Author:}

Kanagasabai Lenin,

Department of EEE,

Prasad V. Potluri Siddhartha Institute of Technology,

Kanuru, Vijayawada, Andhra Pradesh, 520007, India.

Email: gklenin@gmail.com

\section{INTRODUCTION}

Reactive power problem plays an important role in secure and economic operations of power system. Numerous types of methods [1-6] have been utilized to solve the optimal reactive power problem. However many scientific difficulties are found while solving problem due to an assortment of constraints. Evolutionary techniques [7-17] are applied to solve the reactive power problem. This paper proposes Tundra wolf algorithm (TWA) to solve optimal reactive power problem. At first, searching agents has been aggravated to scatter all over the extensive range of probing space to discover the probable prey as an alternative of crowding in the region of the regular local optimal. This phase is also termed as exploration period. In the subsequent exploitation phase, searching agents should have the ability to influence the information of the probable prey to converge in the direction of the global optimal value. In general tracking or hunting action is solitary possessed alpha, beta and delta Tundra wolf while the remaining Tundra wolves are indebted to go behind them that include omega Tundra wolf. In sequence to augment the exploration capability of the search agents, several alterations have been suggested. In the proposed Tundra wolf algorithm (TWA) omega tundra wolf has been taken as searching agent as an alternative of indebted to pursue the first three most excellent candidates. Proposed Tundra wolf algorithm (TWA) has been tested in standard IEEE 14, 30, bus test systems and simulation results show the projected algorithm reduced the real power loss effectively. 


\section{PROBLEM FORMULATION}

Objective of the problem is to reduce the true power loss:

$$
\mathrm{F}=\mathrm{P}_{\mathrm{L}}=\sum_{\mathrm{k} \in \mathrm{Nbr}} \mathrm{g}_{\mathrm{k}}\left(\mathrm{V}_{\mathrm{i}}^{2}+\mathrm{V}_{\mathrm{j}}^{2}-2 \mathrm{~V}_{\mathrm{i}} \mathrm{V}_{\mathrm{j}} \cos \theta_{\mathrm{ij}}\right)
$$

Voltage deviation given as follows:

$$
\mathrm{F}=\mathrm{P}_{\mathrm{L}}+\omega_{\mathrm{v}} \times \text { Voltage Deviation }
$$

Voltage deviation given by:

$$
\text { Voltage Deviation }=\sum_{\mathrm{i}=1}^{\mathrm{Npq}}\left|\mathrm{V}_{\mathrm{i}}-1\right|
$$

Constraint (Equality),

$$
\mathrm{P}_{\mathrm{G}}=\mathrm{P}_{\mathrm{D}}+\mathrm{P}_{\mathrm{L}}
$$

Constraints (Inequality),

$$
\begin{aligned}
& \mathrm{P}_{\text {gslack }}^{\min } \leq \mathrm{P}_{\text {gslack }} \leq \mathrm{P}_{\text {gslack }}^{\text {max }} \\
& \mathrm{Q}_{\mathrm{gi}}^{\min } \leq \mathrm{Q}_{\mathrm{gi}} \leq \mathrm{Q}_{\mathrm{gi}}^{\mathrm{max}}, \mathrm{i} \in \mathrm{N}_{\mathrm{g}} \\
& \mathrm{V}_{\mathrm{i}}^{\text {min }} \leq \mathrm{V}_{\mathrm{i}} \leq \mathrm{V}_{\mathrm{i}}^{\text {max }}, \mathrm{i} \in \mathrm{N} \\
& \mathrm{T}_{\mathrm{i}}^{\min } \leq \mathrm{T}_{\mathrm{i}} \leq \mathrm{T}_{\mathrm{i}}^{\text {max }}, \mathrm{i} \in \mathrm{N}_{\mathrm{T}} \\
& \mathrm{Q}_{\mathrm{c}}^{\min } \leq \mathrm{Q}_{\mathrm{c}} \leq \mathrm{Q}_{\mathrm{C}}^{\max }, \mathrm{i} \in \mathrm{N}_{\mathrm{C}}
\end{aligned}
$$

\section{TUNDRA WOLF ALGORITHM}

In the proposed Tundra wolf algorithm (TWA) hunting behavior of the Tundra wolf has been imitated to design the algorithm for solving the optimal reactive power problem. In Tundra wolf algorithm, the movement of wolf is described by,

$$
\begin{aligned}
& \bar{D}=\left|\bar{C} \bar{X}_{p}(t)-\bar{X}(t)\right| \\
& \bar{X}(t+1)=\bar{X}_{p}(t)-\vec{A} \cdot \vec{D} \\
& \vec{A}=2 a \cdot r_{1}-a \\
& \vec{C}=2 \cdot r_{2} \\
& a=2-2 t / t_{\text {max }}
\end{aligned}
$$

The state of wolves are adjusted by,

$$
\begin{aligned}
& \overrightarrow{D_{\alpha}}=\left|\overrightarrow{C_{1}}, \overrightarrow{X_{\alpha}}-\vec{X}\right| \\
& \overrightarrow{D_{\beta}}=\left|\overrightarrow{C_{2}}, \overrightarrow{X_{\beta}}-\vec{X}\right| \\
& \overrightarrow{D_{\gamma}}=\left|\overrightarrow{C_{3}}, \overrightarrow{X_{\delta}}-\vec{X}\right|
\end{aligned}
$$

When the value of " $\mathrm{A}$ " are located in $[-1,1]$ capriciously, which indicate the procedure of local search perceptibly in this phase the Tundra wolves attack towards the prey. Tundra wolves are forced to make a global search When $|\mathrm{A}|>1$. Through the parameter "a" fluctuation range of " $\mathrm{A}$ " can be decreased. 
In the projected Tundra wolf algorithm (TWA) in order to avoid the searching agents from trapping into the local optimal the converging towards global optimal is divided based on two different conditions. At first, searching agents has been aggravated to scatter all over the extensive range of probing space to discover the probable prey as an alternative of crowding in the region of the regular local optimal. This phase is also termed as exploration period. In the subsequent exploitation phase, searching agents should have the ability to influence the information of the probable prey to converge in the direction of the global optimal value.

$$
\vec{a}=2-1 *\left(\frac{2}{\text { maximum iteration }}\right)
$$

In general tracking or hunting action is solitary possessed alpha, beta and delta Tundra wolf while the remaining Tundra wolves are indebted to go behind them that include omega Tundra wolf. In sequence to augment the exploration capability of the search agents, several alterations have been suggested. In the proposed Tundra wolf algorithm (TWA) omega tundra wolf has been taken as searching agent as an alternative of indebted to pursue the first three most excellent candidates. Escalating the searching agents numbers will perk up the exploration capability of the Tundra wolf wolves in an extensive range. Also it makes the search agents to spread widely during exploration phase. The mode of hunting action done by Tundra wolf will increase the efficiency and time will be saved.

$$
\begin{aligned}
& \overrightarrow{D_{\alpha}}=\left|\overrightarrow{C_{1}}, \overrightarrow{X_{\alpha}}-\vec{X}\right| \\
& \overrightarrow{D_{\beta}}=\left|\overrightarrow{C_{2}}, \overrightarrow{X_{\beta}}-\vec{X}\right| \\
& \overrightarrow{D_{\gamma}}=\left|\overrightarrow{C_{3}}, \overrightarrow{X_{\delta}}-\vec{X}\right| \\
& \overrightarrow{D_{\omega}}=\left|\overrightarrow{C_{4}}, \overrightarrow{X_{\omega}}-\vec{X}\right| \\
& \overrightarrow{X_{1}}=\overrightarrow{X_{\alpha}}-\overrightarrow{A_{1}} \cdot\left(\overrightarrow{D_{\alpha}}\right) \\
& \overrightarrow{X_{2}}=\overrightarrow{X_{\beta}}-\overrightarrow{A_{2}} \cdot\left(\overrightarrow{D_{\beta}}\right) \\
& \overrightarrow{X_{3}}=\overrightarrow{X_{\delta}}-\overrightarrow{A_{3}} \cdot\left(\overrightarrow{D_{\delta}}\right) \\
& \overrightarrow{X_{4}}=\overrightarrow{X_{\omega}}-\overrightarrow{A_{3}} \cdot\left(\overrightarrow{D_{\omega}}\right) \\
& \bar{X}(t+1)=\overrightarrow{X_{1}}+\overrightarrow{X_{2}}+\overrightarrow{X_{3}}+\overrightarrow{X_{4}}
\end{aligned}
$$

Commence,

Search agents population initiated,

a, A,C values are initiated

$\overrightarrow{X_{\alpha}}$ - Indicates the most excellent search agent

$\overrightarrow{X_{\beta}}$ - Indicates the next greatest search agent

$\overrightarrow{X_{\delta}}$ - Indicates the subsequent finest search agent

While ( $\mathrm{t}<$ maximum iteration number)

Modernize the position of the present search agent by $\bar{X}(t+1)=\frac{\overrightarrow{X_{1}}+\overrightarrow{X_{2}}+\overrightarrow{X_{3}}+\overrightarrow{X_{4}}}{4}$

End for

Renew the values of a, A, C

Search agents fitness value should be computed

Modernize the values of $\overrightarrow{X_{\omega}}, \overrightarrow{X_{\beta}}, \overrightarrow{X_{\delta}}, \overrightarrow{X_{\omega}}$

$\mathrm{t}=\mathrm{t}+1$

end while

Return with $\overrightarrow{X_{\alpha}}$ 


\section{SIMULATION RESULTS}

At first in standard IEEE 14 bus system [18] the validity of the proposed Tundra wolf algorithm (TWA) has been tested, Table 1 shows the constraints of control variables Table 2 shows the limits of reactive power generators and comparison results are presented in Table 3.

Then the proposed Tundra wolf algorithm (TWA) has been tested, in IEEE 30 Bus system. Table 4 shows the constraints of control variables, Table 5 shows the limits of reactive power generators and comparison results are presented in Table 6.

Table 1. Constraints of control variables

\begin{tabular}{cccc}
\hline System & Variables & $\begin{array}{c}\text { Minimum } \\
(\mathrm{PU})\end{array}$ & $\begin{array}{c}\text { Maximum } \\
(\mathrm{PU})\end{array}$ \\
\hline \multirow{2}{*}{$\begin{array}{c}\text { Generator } \\
\text { Bus } 14\end{array}$} & $\begin{array}{c}\text { Voltage } \\
\text { Transformer } \\
\text { Tap }\end{array}$ & 0.95 & 1.1 \\
& VAR Source & 0.9 & 1.1 \\
\hline
\end{tabular}

Table 2. Constrains of reactive power generators

\begin{tabular}{cccc}
\hline System & Variables & $\begin{array}{c}\text { Q Minimum } \\
(\text { PU) }\end{array}$ & $\begin{array}{c}\text { Q Maximum } \\
(\text { PU) }\end{array}$ \\
\hline \multirow{2}{*}{ IEEE 14 } & 1 & 0 & 10 \\
Bus & 2 & -40 & 50 \\
& 3 & 0 & 40 \\
& 6 & -6 & 24 \\
& 8 & -6 & 24 \\
\hline
\end{tabular}

Table 3. Simulation results of IEEE -14 system

\begin{tabular}{|c|c|c|c|c|c|c|}
\hline Control variables & Base case & MPSO [19] & PSO [19] & EP [19] & SARGA [19] & TWA \\
\hline$V G-1$ & 1.060 & 1.100 & 1.100 & $\mathrm{NR}^{*}$ & $\mathrm{NR}^{*}$ & 1.012 \\
\hline$V G-2$ & 1.045 & 1.085 & 1.086 & 1.029 & 1.060 & 1.018 \\
\hline$V G-3$ & 1.010 & 1.055 & 1.056 & 1.016 & 1.036 & 1.013 \\
\hline$V G-6$ & 1.070 & 1.069 & 1.067 & 1.097 & 1.099 & 1.018 \\
\hline$V G-8$ & 1.090 & 1.074 & 1.060 & 1.053 & 1.078 & 1.023 \\
\hline Tap 8 & 0.978 & 1.018 & 1.019 & 1.04 & 0.95 & 0.921 \\
\hline Tap 9 & 0.969 & 0.975 & 0.988 & 0.94 & 0.95 & 0.920 \\
\hline Tap 10 & 0.932 & 1.024 & 1.008 & 1.03 & 0.96 & 0.929 \\
\hline$Q C-9$ & 0.19 & 14.64 & 0.185 & 0.18 & 0.06 & 0.128 \\
\hline$P G$ & 272.39 & 271.32 & 271.32 & $\mathrm{NR} *$ & $\mathrm{NR}^{*}$ & 271.76 \\
\hline$Q G$ (Mvar) & 82.44 & 75.79 & 76.79 & $\mathrm{NR}^{*}$ & $\mathrm{NR}^{*}$ & 75.79 \\
\hline Reduction in PLoss (\%) & 0 & 9.2 & 9.1 & 1.5 & 2.5 & 26.13 \\
\hline Total PLoss (Mw) & 13.550 & 12.293 & 12.315 & 13.346 & 13.216 & 10.009 \\
\hline
\end{tabular}

Table 4. Constraints of control variables

\begin{tabular}{cccc}
\hline System & Variables & $\begin{array}{c}\text { Minimum } \\
(\mathrm{PU})\end{array}$ & $\begin{array}{c}\text { Maximum } \\
(\mathrm{PU})\end{array}$ \\
\hline \multirow{3}{*}{$\begin{array}{c}\text { Generator } \\
\text { Voltage }\end{array}$} & 0.95 & 1.1 \\
Bus & $\begin{array}{c}\text { Transformer } \\
\text { Tap }\end{array}$ & 0.9 & 1.1 \\
& VAR Source & 0 & 0.20 \\
\hline
\end{tabular}

Table 5. Constrains of reactive power generators

\begin{tabular}{cccc}
\hline System & Variables & $\begin{array}{c}\text { Q Minimum } \\
(\mathrm{PU})\end{array}$ & $\begin{array}{c}\text { Q Maximum } \\
(\mathrm{PU})\end{array}$ \\
\hline \multirow{2}{*}{ IEEE 30 } & 1 & 0 & 10 \\
Bus & 2 & -40 & 50 \\
& 5 & -40 & 40 \\
& 8 & -10 & 40 \\
& 11 & -6 & 24 \\
& 13 & -6 & 24 \\
\hline
\end{tabular}

Table 6. Simulation results of IEEE -30 system

\begin{tabular}{|c|c|c|c|c|c|c|}
\hline Control variables & Base case & MPSO [19] & PSO [19] & EP [19] & SARGA [19] & TWA \\
\hline$V G-1$ & 1.060 & 1.101 & 1.100 & NR* & NR* & 1.019 \\
\hline$V G-2$ & 1.045 & 1.086 & 1.072 & 1.097 & 1.094 & 1.020 \\
\hline$V G-5$ & 1.010 & 1.047 & 1.038 & 1.049 & 1.053 & 1.018 \\
\hline$V G-8$ & 1.010 & 1.057 & 1.048 & 1.033 & 1.059 & 1.026 \\
\hline$V G-12$ & 1.082 & 1.048 & 1.058 & 1.092 & 1.099 & 1.031 \\
\hline VG-13 & 1.071 & 1.068 & 1.080 & 1.091 & 1.099 & 1.029 \\
\hline Tap11 & 0.978 & 0.983 & 0.987 & 1.01 & 0.99 & 0.935 \\
\hline Tap12 & 0.969 & 1.023 & 1.015 & 1.03 & 1.03 & 0.931 \\
\hline Tap15 & 0.932 & 1.020 & 1.020 & 1.07 & 0.98 & 0.927 \\
\hline Tap36 & 0.968 & 0.988 & 1.012 & 0.99 & 0.96 & 0.937 \\
\hline QC10 & 0.19 & 0.077 & 0.077 & 0.19 & 0.19 & 0.091 \\
\hline QC24 & 0.043 & 0.119 & 0.128 & 0.04 & 0.04 & 0.121 \\
\hline$P G(\mathrm{MW})$ & 300.9 & 299.54 & 299.54 & $\mathrm{NR}^{*}$ & $\mathrm{NR}^{*}$ & 297.69 \\
\hline$Q G$ (Mvar) & 133.9 & 130.83 & 130.94 & $\mathrm{NR}^{*}$ & NR* & 131.39 \\
\hline Reduction in PLoss (\%) & 0 & 8.4 & 7.4 & 6.6 & 8.3 & 20.14 \\
\hline Total PLoss (Mw) & 17.55 & 16.07 & 16.25 & 16.38 & 16.09 & 14.014 \\
\hline
\end{tabular}




\section{CONCLUSION}

In this paper Tundra wolf algorithm (TWA) successfully solved the optimal reactive power problem. Proposed algorithm perk up the exploration capability of the Tundra wolf wolves in an extensive mode. Also it makes the search agents to spread widely during exploration phase. In the proposed Tundra wolf algorithm (TWA) omega tundra wolf has been taken as searching agent as an alternative of indebted to pursue the first three most excellent candidates. This mode of hunting action increases the efficiency. Proposed Tundra wolf algorithm (TWA) has been tested in standard IEEE 14, 30 bus test systems and simulation results show the projected algorithm reduced the real power loss. Percentage of real power loss reduction has been improved when compared to other standard algorithms.

\section{REFERENCES}

[1] K. Y. Lee, "Fuel-cost minimisation for both real and reactive-power dispatches," Proceedings Generation, Transmission and Distribution Conference, vol. 131, no. 3, pp. 85-93.1984.

[2] N. I. Deeb. "An efficient technique for reactive power dispatch using a revised linear programming approach," Electric Power System Research, vol. 15, no. 2, pp. 121-134, 1998.

[3] M. R. Bjelogrlic, M. S. Calovic, B. S. Babic, "Application of Newton's optimal power flow in voltage/reactive power control," IEEE Trans Power System, vol. 5, no. 4, pp. 1447-1454, 1990.

[4] S. Granville, "Optimal reactive dispatch through interior point methods," IEEE Transactions on Power System, vol. 9, no. 1, pp. 136-146, 1994.

[5] N. Grudinin., "Reactive power optimization using successive quadratic programming method," IEEE Transactions on Power System, vol. 13, no. 4, pp. 1219-1225, 1998.

[6] Ng Shin Mei, R.; Sulaiman, M.H.; Mustaffa, Z.; Daniyal, H., "Optimal reactive power dispatch solution by loss minimization using moth-flame optimization technique," Appl. Soft Comput., vol. 59, pp. 210-222, 2017.

[7] Chen, G.; Liu, L.; Zhang, Z.; Huang, S., "Optimal reactive power dispatch by improved GSA-based algorithm with the novel strategies to handle constraints" Appl. Soft Comput., vol. 50, pp. 58-70, 2017.

[8] Naderi, E.; Narimani, H.; Fathi, M.; Narimani, M.R, "A novel fuzzy adaptive configuration of particle swarm optimization to solve large-scale optimal reactive power dispatch," Appl. Soft Comput., vol. 53, 441-456, 2017.

[9] Heidari, A.A.; Ali Abbaspour, R.; Rezaee Jordehi, A., "Gaussian bare-bones water cycle algorithm for optimal reactive power dispatch in electrical power systems," Appl. Soft Comput., vol. 57, pp. 657-671, 2017.

[10] Mahaletchumi Morgan, Nor Rul Hasma Abdullah, Mohd Herwan Sulaiman, Mahfuzah Mustafa, Rosdiyana Samad. "Benchmark Studies on Optimal Reactive Power Dispatch (ORPD) Based Multi-objective Evolutionary Programming (MOEP) Using Mutation Based on Adaptive Mutation Adapter (AMO) and Polynomial Mutation Operator (PMO)," Journal of Electrical Systems, 2016.

[11] Rebecca Ng Shin Mei, Mohd Herwan Sulaiman, Zuriani Mustaffa, "Ant Lion Optimizer for Optimal Reactive Power Dispatch Solution,” Journal of Electrical Systems, Special Issue AMPE2015, pp. 68-74, 2016.

[12] P. Anbarasan, T. Jayabarathi, "Optimal reactive power dispatch problem solved by symbiotic organism search algorithm," Innovations in Power and Advanced Computing Technologies, 2017.

[13] Gagliano A., Nocera F. "Analysis of the performances of electric energy storage in residential applications," International Journal of Heat and Technology, vol. 35, no. 1, pp. S41-S48, 2017.

[14] Caldera M., Ungaro P., Cammarata G., Puglisi G., "Survey-based analysis of the electrical energy demand in Italian households," Mathematical Modelling of Engineering Problems, vol. 5, no. 3, pp. 217-224, 2018.

[15] M. Basu, "Quasi-oppositional differential evolution for optimal reactive power dispatch," Electrical Power and Energy Systems, vol. 78, pp. 29-40, 2016.

[16] Gai-Ge Wang, "Moth search algorithm: a bio-inspired metaheuristic algorithm for global optimization problems," Memetic Comp, 2016.

[17] L. Li, L. Sun, J. Guo, J. Qi, B. Xu, and S. Li, "Modified Discrete Grey Wolf Optimizer Algorithm for Multilevel Image Tresholding," Computational Intelligence and Neuroscience, 2017.

[18] IEEE, "The IEEE-test systems", 1993. http://www.ee.washington.edu/trsearch/pstca/.

[19] Ali Nasser Hussain, Ali Abdulabbas Abdullah and Omar Muhammed Neda, "Modified Particle Swarm Optimization for Solution of Reactive Power Dispatch", Research Journal of Applied Sciences, Engineering and Technology, vol. 15, no. 8, pp. 316-327, 2018. 